\title{
The Overall Design of Humanoid Cross-Stitch Machine Based On Computer Embroidery
}

\author{
Hai-bin Zhang; Li-chao Tang; Cheng-hao Huang \\ School of Electronic \&Engineering, Heilongjiang University, Harbin 150080, China
}

\begin{abstract}
Computer embroidery is a kind of cross-stitch automatic machine which is very common on the market at present, it can complete the different colors and styles of embroidery according to the cross stitch pattern, but for the embroidered cloth without cross grid requirements, and the quality of cross stitch also has the certain problems. What the design of humanoid cross-stitch machine considers is to imitate human hand embroidered action. The overall design of the whole machine, thread cutting mechanism, line stop mechanism, embroidery needle clamping and line library achieves completing the automatic operation on the basis of quality assurance.
\end{abstract}

KEYWORD: Computer Embroidery; Cross Stitch; Mechanism Design; Automatic Operation

\section{GENERAL INSTRUCTIONS}

Computer embroidery machine is composed of host (mechanical part) and the controller. Embroidery machine host is composed by the nose, bedplate, actuator, frame, and so on[1]. When the computer embroidery machine works, it's needle bar with embroidery needle and line does the up and down movement, and the stabbed embroidery move with the embroidered box along the $\mathrm{X}, \mathrm{Y}$ direction and get embroidery pattern[2]. The embroidery part is composed of spindle motor, variable speed device, photoelectric encoder, the drive shaft, shaft, bobbin, needle bar drive mechanism, selects the line machine and so on, through mutual cooperation movement between the needle bar and the hook to complete the embroidery process[3]. Movement principle of the mechanism was evolved from the sewing machine, defect is that the online or offline twisted which makes the quality of embroidered cloth in one place embroider line fault, and all the embroidered cloth embroider line will be affected, which undermining the quality of the embroidery. But the humanoid cross-stitch embroidery machine completely changed the situation, first of all, at the request of the embroidered cloth has greatly improved, it uses the embroidered cloth which is used in the manual cross-stitch, on the one hand, it makes the cross stitch more stereo feeling, the quality is guaranteed, and at the same time it can save labor in the industry, and complete the production automation.
The overall structure of humanoid cross-stitch machine mainly includes the following parts: $\mathrm{X}, \mathrm{Y}$, $\mathrm{Z}$ three directions of motion platform design, embroidered cloth fixed part, embroidery needle clamping mechanism, the cutting mechanism, a mechanism, line and shift mechanism.

\section{THE DESIGN OF PLATFORM}

The design of Machine tool guide refers to "Review of machine tool technology"[4]. The X direction movement is achieved by the servo motor and worm gear reducer drive axis transmission, the optical axis are respectively provided with bevel gear, the two bevel gear meshing transmission and respectively drive the ball screw drive, screw are used the traditional structure of rolling guide so as to realize the $\mathrm{X}$ direction of the movement[5].

The Y direction of the movement along with $\mathrm{X}$ motion platform, after the $\mathrm{X}$ direction has been ensured, $\mathrm{Y}$ direction is also achieved by the servo motor and worm gear reducer drive axis transmission, motor directly drive the ball screw driving the $Y$ direction of the work platform to realize the $Y$ direction movement.

The vertical motion of $\mathrm{Z}$ direction platform movement along with the motion platform of $\mathrm{Y}$ direction, after determining the $\mathrm{X}, \mathrm{Y}$ direction of movement, the $\mathrm{Z}$ direction of working platform drives the embroidery needle clamping mechanism downward movement to complete the action of 
embroidery. The $\mathrm{Z}$ direction is achieved by the servo motor and the planet reducer to drive the ball screw to complete the $\mathrm{Z}$ direction of movement.

\section{EMBROIDERED CLOTH FIXED}

Cross-stitch cloth can be divided into plastic cloth, cotton and linen fabrics, because of these fabrics have elasticity, and the embroidered cloth gap between the grid is very small, so in order to achieve accurate embroidered with beautiful patterns, it is necessary to accurately fixed embroidered cloth. Embroidered cloth fixing structure mainly consists of the following parts:

\subsection{Adjustable frame}

Considering the current market sizes of many kinds of embroidered cloth and diverse, so it is necessary to design a structure that can meet the size variable condition. At first, to design a frame, the size of which should take into account the maximum embroidered cloth size of $1000 * 1000$, frame is designed into square steel hollow, the two frame is transversely arranged on a rectangular square steel, which can move in the frame. Adjust the embroidered cloth size to what we need after fixed with bolts, embroidered cloth is placed in a rectangular tuned flat steel to complete the embroidered cloth positioning of different sizes.

\subsection{The width direction embroidered cloth clamping and tightening}

Embroidered cloth need accurate positioning and clamping in two directions, after the embroidered cloth have good location, it needs the embroidered cloth clamp. The width direction using two plates to press the edges of embroidered cloth, considering that not to damage the embroidered cloth, the pressure plate is pressed on the outer edge of embroidered cloth, the outer of press left some size to two plates by a bolt, so as to realize the clamping of embroidered cloth. In order to ensure the accurate positioning of embroidered cloth in the coordinate of machine tool, this paper design a coordinate dimensions in the plate, and the plate design with holes, with a pin fixing the embroidered cloth in the corresponding coordinates, and then using the platen to clamp.

\subsection{The length direction embroidered cloth clamping and tightening}

Width of embroidered cloth rack designed in this paper is based on the current market's biggest embroidered cloth size $1000 \mathrm{~mm}$, but the length size is a center size, so when the rack of embroidered cloth is not the design size, we need to consider how to fix this variable embroidered cloth. The structure as the following 1 show:

In the width direction, the embroidered cloth has accurately position, when fixed the length direction, due to the clamping embroidered cloth have interference between the plates, so the method can't be the same with the width. The design of the clamping mechanism in this paper is as follows:

Because of the variable length of embroidered cloth, so we use the roller to achieve the tension, that is connecting the embroidered cloth with the roller. With this piece of embroidered cloth and the embroider cloth that needed to connect the stitch embroidering cloth by pressing and rotating the wheel, to achieve the embroidered cloth tightening. When connecting the two embroidered cloth with the press plate, considering the variable size of embroidered cloth, so using the connection plate at both ends, considering the actual size, the intermediate can be connected by bolts according to the connection pieces of plate, after the clamping and using the roller to brace.

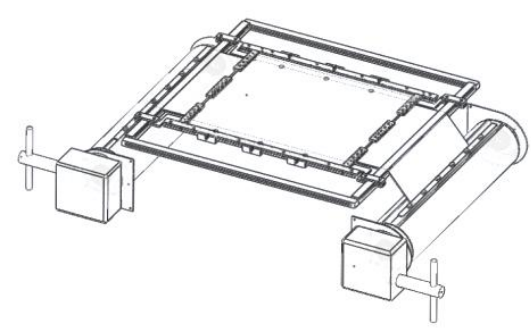

Figure 1. Embroidered cloth fixing mechanism.

\section{EMBROIDERY NEEDLE CLAMPING MECHANISM}

Embroidery needle clamping mechanism is used to realize the embroidery needle clamping and turning, mainly consists of two aspects, on one hand, how to realize the embroidery needle clamping, the embroidery needle can move along the $\mathrm{Z}$ direction of track, on the other hand, when the clamping embroidery needle move at the top, how to flip the embroidery needle to stitch embroidery action.

Embroidery needle clamping adopts the push-pull electromagnet, power on and off by controlling the magnetic attraction, push rod move back, to complete the embroidery needle clamping. "A connecting rod type clamping mechanism symmetry optimization" design the optimization of the clamping mechanism [6], clamp body holding mechanism part is a cylinder at the end of the intermediate machining gap embroidery needle thickness, which is used to put the embroidery needle for clamping, placed the push-pull electromagnet mechanism by the side of cylinder gap, then it can realize the embroidery needle clamping, the clamping mechanism move along the 
$\mathrm{Z}$ direction by the screw drive, which can realize the reciprocating embroidery needle up and down movement.

Embroidery needle is reversed in order to realize process imitating handmade embroidery, after a direction of embroidery to another direction of movement, the embroidery needle alignment embroidered cloth. In this paper, the use of stepper motor by controlling the pulse control clamping mechanism rotated 180 degrees, the embroidery needle turnover.

\section{THE AUXILIARY MECHANISM}

\subsection{The shear line}

Thread cutting mechanism of computer embroidery machine is a relative independent electromechanical integration system, it is composed of a fixed knife, knife, cutting line electromagnet, shear line cam and connecting rod mechanism, the retainer electromagnet and the corresponding mechanism, hook line electromagnet and wire clamping mechanism. The movement of the shear line completed by the mechanical and electrical control closely to keep the continuous automatic action of the bottom line arrangement、 cut and thread [7]. The design of shear line mechanism refers to the "cut the design and application of line platform combined structure "[8].

The first is to determine the location of the shear line. The line shearing mechanism designed below the embroidered cloth, the next color embroidery thread embroidery action after the shear line, so the shear line body position must ensure the length cut embroider line will not cause interference to the next action, namely, embroider line not winding down a color embroidery thread. In addition, in order to ensure the cut embroider line can be hidden line in a follow-up work, to make the beautiful embroidered cloth. So the length of the line can't be too long, to prevent interference, can't be too short, to prevent breakage and subsequent hidden line. Through practical investigation and personal experience, as long as guarantee that left the shear line length is about $5 \mathrm{~mm}$, so the thread cutting mechanism is positioned on the embroidered cloth around the bottom of $6 \mathrm{~mm}$ position.

The second is the design of the shear line mechanism, to design a support block to meet the requirements of the position and the size, and design two crosses hinged on the supporting block blade, driving with electromagnet, through the electromagnet attraction towards shear line. In order to achieve cutting off, two blades can automatically reset, connected by a spring between the two blades, power can be automatically released by the action of the spring, so as to realize the complete actions of shear line.

\subsection{The line blocked}

The line blocked is a mechanism for preventing interferences between lines in the process of imitation handmade embroidery. In the embroidery needle movement process, using the line agencies to poke the moving embroidery thread, when the embroidery thread move upward, at the same time the thread blocking mechanism poke a certain angle, and when the embroidery needle downwards, line stop mechanism move the opposite direction back to the initial position, until the completion of the whole of the direction of the embroidery action.

The line blocked structure as follows: In order to realize the swinging baffle action, using the driving steering gear. The actuator's output shaft drives a baffle plate, through the reciprocating swing actuator movement to achieve the baffle angle, so as to realize the wire blocking action. Line stop mechanism should also meet the up-down symmetry, namely in the upper and lower parts of embroidered cloth must have line stop mechanism.

\subsection{Line library and Line changing mechanism}

Automatic winding machine forms are different, but the basic principles are the same. The winding mechanism drives the winding framework rotation in accordance with the provisions, the winding wire winding frame. At the same time, the electromagnetic providing the line position is determined by the winding mechanism, and to guarantee the line position is controlled by the control unit according to a certain mode changing. Thus, the electromagnetic line can be winding to winding skeleton in accordance with the law [9], besides the automatic winding machine of this kind is parallel arranged.

The design of this line library is cylinder mechanism, it can meet the design requirements, at the same time, it saves space effect. As shown in Figure 2, around the cylinder on the whole circumference processes number slot evenly, according to the number of the specific color of the spiraea, insert the bracket slot that have designed, which is used to support the embroidery needle mechanism. The embroidery needle mechanism is interaction with two supporting stand body, and the two frame body clamp embroidery needle, at the same time, the frame body of the two clamping the embroidery needle clamp in stent design. The whole line base motion is driven by the motor, when we need for a color of the embroidery thread, driving the motor to rotate to the embroider line color, using the design of clamping mechanism for holding the support frame of the clamped embroidery needle embroidery do the action next.

The computer embroidery machine performs automatic shear line, this action is achieved by 
buckle line, shear line and hook line ordination completed [10]. But the humanoid cross stitch machine does not involve the buckle line and hook line such action, in order to realize changing the line fast, improve processing efficiency, no additional line change mechanism designed, directly through the position limit, the thread library mechanism is placed in the Y direction motion platform, while the $\mathrm{Z}$ direction of the movement is along with the $\mathrm{Y}$ direction of the platform motion, this can achieve changing line at any time. When we need to change the line, driving the motor to rotate to the desired color embroidery line, and the clamping mechanism moves up to the embroidery needle, clamping embroidery needle moves downward.

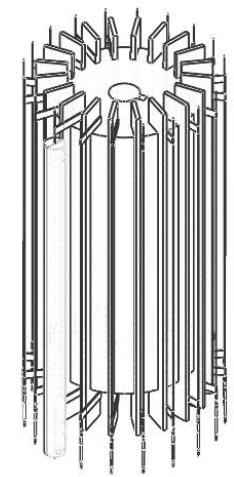

Figure 2. Line library.

\section{CONCLUSIONS}

Through the design of the above several parts structure, realized the following functions:

(1) The design of $\mathrm{X}, \mathrm{Y}, \mathrm{Z}$ work platform realize the embroidery needle can move to the specified coordinates according to the motor, and the symmetric design of $\mathrm{Y}$ and $\mathrm{Z}$ platform realize the reciprocating motion of the needle embroidery.

(2) The design of embroidered cloth fixing structure realizes the precise location of embroidered cloth by bolts, so that the structure of the cross stitch cloth that have strict requirements had a very important influence on the quality of cross stitch.

(3) The design of embroidery needle clamping mechanism can realize embroidery needle holding different color embroidery thread, and up and down reciprocating motion in the $\mathrm{Z}$ platform, at the same time, it can realize the flip embroidery needle.

(4) The design of stop line and shear line mechanism is simple and easy to manufacture, it can guarantee the embroidery needle does not interfere in imitation of hand motion process. A cylinder line library mechanism can provide different colors and spiraea species for the whole cross stitch, also can save cost and space.

\section{REFERENCES}

[1] Gu Fengxiang. Computer embroidery machinecontrol system based on DSP. Zheng Jiang, Zhejiang University of Technology, 2007.

[2] Zhao Yanwen, Wu Shili, Fang Xiaochu. The working principle of $\mathrm{Fu} \mathrm{Yi}$ brand computer embroidery machine. Journal of Wuhan University of Science and Engineering, 2000, 13(2):90-91.

[3] Cao Xilin, Lv Zhijun. Analysis of the mechanical principle of computerized embroidery machine. Mechanical management and development. 2001, 2(30):44.

[4] Qu Chongnian, Wu Liangsheng, Xiao Yichuan, Zhang Shihai. Review of machine tool technology. Manufacturing technology and machine tool, 2012, 1:3233.

[5] Zheng Qianying. High rigidity design and precision analysis of rolling linear guide. Ha Erbin: Harbin Institute of Technology, 2013.

[6] Ding Xiangfang, Han Xiaojian, Liu Jian. A connecting rod type clamping mechanism symmetry optimization. Mechanical design, 2013, 30(6): 54-55.

[7] Zhao Yuling, Zhou You, Li Chunfu. Study on the control method of the shear line length of embroidery machine. Electrical and mechanical product development, 2011, 24(2):29-29.

[8] Yang Yi, Sun Yuchao, Xu Shimu. Shear line platform design and application of combined structure. Machinery manufacturing, 2013, 51(592): 63-64.

[9] Pang Guihan. Research and development of computer automatic winding machine. Dalian: Dalian University of Technology, 2004.

[10] Wang Yong. Design and Realization of computer embroidery machine color changing shear line controller. Nanjing: Nanjing University of Technology, 2009. 